\title{
Hyponeurotrophinemia in Serum of Women with Polycystic Ovary Syndrome as a Low Grade Chronic Inflammation
}

\author{
Farideh Zafari Zangeneh1*, Maryam Bagheri1, Mohammad Mehdi Naghizadeh2 \\ ${ }^{1}$ Reproductive Health Research Center, Tehran University of Medical Sciences, Tehran, Iran \\ ${ }^{2}$ Department of Community Medicine, Medical Faculty, Fasa University of Medical Sciences, Fasa, Iran \\ Email: ${ }^{*}$ zangeneh14@gmail.com
}

Received 10 June 2015; accepted 18 August 2015; published 21 August 2015

Copyright (C) 2015 by authors and Scientific Research Publishing Inc.

This work is licensed under the Creative Commons Attribution International License (CC BY).

http://creativecommons.org/licenses/by/4.0/

(c) (†) Open Access

\begin{abstract}
Introduction: This study aimed to discuss about neuroimmune-pathophysiology of polycystic ovary syndrome (PCOS). Nerve growth factor (NGF) as modulator of neuro-endocrine-immune (NEI) system plays a critical role in tissue survival and homeostasis maintenance. It is a strong marker for sympathetic nerve activity. Women with PCO have enhanced ovarian NGF production. Over the past few decades, PCOS has been discussed as a low grade chronic inflammatory disease. In this study, we investigated the neuromodulator role of serum NGF and inflammatory cytokines (IL-1 $\alpha, \beta, 17 \mathrm{~A}$ and TNF- $\alpha$ ) in women with PCOS. Material and Methods: 171 patients were investigated in two groups: study $(n=85$ PCO) and control $(n=86)$. Serum levels of NGF- $\alpha$ and interleukins IL-1 $\alpha$, IL-1 $\beta$, IL-17A and TNF $\alpha$ were determined in both groups by ELISA kit. Results: Data of this study showed that the level of NGF- $\alpha$ and IL-17A in serum of PCO women were lower than control group $(p<0.001)$. The serum levels of IL-1 $\alpha$, IL-1 $\beta$ were higher than control group in PCO women $(p<0.001)$. Conclusion: Probably inflammatory background in PCOS is the main cause of increased serum levels of IL-1 $\alpha$, IL-1 $\beta$. Reduction of IL-17A and NGF in serum of PCO patients might be under the direct influence of the hyperactivity of sympathetic nervous system (SNS).
\end{abstract}

\section{Keywords}

Polycystic Ovary Syndrome (PCOS), Nerve Growth Factor $\alpha$ (NGF $\alpha$ ), Sympathetic Nervous System (SNS), Interleukin $1 \alpha, 1 \beta, 17 \mathrm{~A}, \mathrm{TNF} \alpha$

\footnotetext{
${ }^{*}$ Corresponding author.
}

How to cite this paper: Zangeneh, F.Z., Bagheri, M. and Naghizadeh, M.M. (2015) Hyponeurotrophinemia in Serum of Women with Polycystic Ovary Syndrome as a Low Grade Chronic Inflammation. Open Journal of Obstetrics and Gynecology, 5, 459-469. http://dx.doi.org/10.4236/ojog.2015.59067 


\section{Introduction}

\subsection{Polycystic Ovary Syndrome (PCOS)}

PCOS is a complex, multifaceted, heterogeneous disorder, affecting $4 \%$ to $18 \%$ of reproductive-aged women and is associated with reproductive, metabolic and psychological dysfunction [1]. A 2004 consensus conference added another diagnostic criterion, multicystic ovarian morphology (ultrasonographic) and required two of the three criteria to support the diagnosis [2]. The precise etiology of the disease is so far still unknown, but there are indications that PCOS is associated with hyperactivity in the sympathetic nervous system [3]. Findings that support the involvement of the sympathetic nervous system in the pathophysiology of PCOS are that the catecholaminergic nerve fibers in the polycystic ovaries of women with PCOS are denser than in normal ovaries [4] [5] and the metabolism of norepinephrine (N) in adolescents suffering from the disease is impaired [6]. Many of the common features of PCOS, such as central obesity, hyperinsulinaemia and obstructive sleep apnoea (OSA) are associated with chronic sympathetic overactivity, suggesting that sympathoexcitation may be involved in the pathogenesis of this condition. Nerve growth factor (NGF) is a strong marker for sympathetic nerve activity and recently it is demonstrated that NGF production is higher in women with ovarian cysts [7]. Rodent models of polycystic ovaries have shown that ovarian sympathetic outflow may be increased, accompanied by elevated intra-ovarian synthesis of NGF which may be involved in initiation of ovarian pathology. The nervous and immune systems are involved in adapting the body to the environment and in maintaining homeostasis [8]. Normal reproductive functioning in healthy, fertile women exists due to the presence of unique immunologic barriers, and also due to harmonic functioning of immunoregulatory by neuro-immunologic mechanisms.

\subsection{Chronic Low-Grade Subclinical Inflammation in Ovary}

In recent decades, PCOS is discussed as a chronic inflammatory disease [9]. Low-grade chronic inflammation seems to play an essential role in insulin resistance and its metabolic consequences [10] and may also play a role in the pathogenesis of PCOS [11]. In female reproductive function neuropeptides, growth factors and cytokines are expressed in reproductive organs and tissues, where they interact with afferent endocrine messages to modulate cell proliferation and differentiation, local hormone secretion and vascular function. These events regulate complex processes such as gonadotropin plasticity, ovulation, implantation and parturition [12]. During female reproductive life, the role of the cytokine cascade and regulation of the expression of cytokine genes in the processes of fertilization is very complex. Studies show Low-grade chronic inflammation is reflected by minor but significant increases in circulating levels of known inflammatory and acute phase proteins such as interleukin IL-1, IL-6, tumor necrosis factor (TNF) and serum C-reactive protein (CRP). Cytokines and other inflammatory mediators can signal the brain, and the importance of this neuroimmune-endocrine cross-talk becomes evident in the case of autoimmune and inflammatory diseases. One of the most prominent mediators of inflammation is the interleukin-1 (IL-1) family that consists of three different cytokines, the pro inflammatory cytokines IL- $1 \alpha$, IL-1 $\beta$ and the physiological antagonist IL-1 receptor antagonist (IL-1RA) [13]. IL-1 is a multifunctional cytokine and it has highly inflammatory features in reproductive biology and is believed to affect the processes of fertilization and implantation. Smagin et al. in 1996 showed that noradrenergic terminals in the hypothalamus play a role in the IL-l-induced activation of the HPA axis [14]. It is possible that noradrenergic terminals in the hypothalamus play a role in the IL-l-induced activation of the HPA axis [15]. Kolbus et al., in 2007 have shown that a common polymorphism of the IL- $1 \alpha$ gene is associated with the presence of PCOS and with clinical parameters of women affected by this condition [16]. Administration of IL-1 $\beta$ to humans initiates a cascade of metabolic, hematologic, and cardiovascular events. Cardiovascular responses that occur early after IL- $1 \beta$ administration in humans are most likely the result of adrenergic stimulation possibly through its effect on the central nervous system [17]. Atsumi et al., in 2014 have redefined inflammation as local activation of the inflammation amplifier, which causes an accumulation of various immune cells followed by deregulation of local homeostasis. The inflammation amplifier is activated by the stimulation of cytokines, such as TNF- $\alpha$, IL-17, and noradrenaline, resulting in the subsequent expression of various target genes for chemokine [18].

\subsection{Nerve Growth Factor (NGF) as Modulator of Neuro-Endocrine-Immune (NEI) System}

NGF is the best known neurotrophin, which operates through multiple pathways to regulate physiological homeostasis. In fact NGF is involved in the modulation of the neuro-endocrine-immune (NEI) system and has an important role in maintaining homeostasis of these systems. NGF is a strong marker for sympathetic nerve ac- 
tivity and recently it was demonstrated that women with PCOS has enhanced ovarian NGF production [7].

\subsection{Ovary \& NGF}

NGF has important functions in the maintenance of viability and proliferation of neuronal and non-neuronal cells, such as certain ovarian cells. Expression of NGF and its receptors is localized in ovarian cells (oocyte, granulosa, theca and interstitial cells) from several species, which suggests that NGF and its receptors may regulate some ovarian functions such as follicular survival or development [8]. Under normal conditions, NGF acting via high-affinity tyrosine receptor kinase A (trk A) receptors facilitates the ovulatory process [19]. The ovary is no exception because the development of follicular cysts in rats treated with estradiol valerate (EV) is associated with sustained overproduction of NGF in the gland [20]. Additional studies showed that a selective increase in intra-ovarian NGF content via grafting of cells genetically engineered to produce NGF initiated several of the structural and functional alterations associated with the development of follicular cysts in the rat ovary, including appearance of pre-cystic structures, an increase in the number of apoptotic follicles, and hyperandrogenemia [21]. Thus, ovarian NGF may not only contribute to regulating normal follicle growth, but if produced at persistently elevated levels, it may also initiate ovarian pathology. A potential contribution of an excess of intraovarian NGF to human PCO can be inferred from the findings of sympathetic hyper-innervation of the ovary from PCOS patients [22] [23]. To determine whether a chronic excess of endogenous NGF production is capable of causing ovarian pathology, Gore-Langton et al. in 1994 generated transgenic mice carrying the NGF gene under the control of the 17- $\alpha$ hydroxylase/C17-20 lyase (17- $\alpha \mathrm{OH})$ promoter. Because this gene is specifically expressed in androgen-producing cells [5], these animals show selective over expression of NGF in thecal/interstitial cells of the ovary, the predominant site of NGF production in rodents [24]. The results show that the ovaries of NGF-overexpressing transgenic mice have an accumulation of antral follicles, which appear to be arrested at a medium-intermediate stage. This developmental arrest is accompanied by enhanced granulosa cell apoptosis, increased androgen production in response to increased FSH-like activity [pregnant mare serum gonadotropin (PMSG)] and a heightened prevalence of follicular cysts in response to a sustained elevation of serum LH-like levels [human chorionic gonadotropin (hCG)]. In keeping with these findings, NGF overproducers have reduced fertility and shortened reproductive life span [25]. Dissen et al., in 2009 showed that follicular fluid, collected from PCOS patients undergoing in vitro fertilization, is almost a 2-fold increase in mean NGF levels with respect to follicular fluid obtained from non-PCOS ovaries and they showed that NGF of granulosa cells in women with PCOS is more than cells from non-PCOS ovaries. These results suggest that overproduction of ovarian NGF is a component of PCO morphology in both humans and rodents [7]. Inflammatory cytokines such as IL- $1 \beta$, TNF $\alpha$ and IL- 6 are able to modify the basal production of NGF in the organism and induce the synthesis of NGF in a variety of cell types and tissues. Since the endogenous levels of NGF are substantially increased in the inflamed tissues, it is not surprising that during the inflammatory process the innervation of these tissues is not static. Inflammation induces marked alterations in nerve fiber distribution and influences the phenotype of innervating neurons inducing the expression of neurotransmitters, neuromodulators, ion channels, $\mathrm{G}$ protein-coupled receptors and growth-associated structural proteins [26].

\subsection{NGF \& Anti-Inflammatory Action}

From experimental and human data it can be concluded that NGF in parallel with the sympathetic nervous system can maintain immune cells in a state of standby to potential danger signals. NGF can enhance mediator release, like norepinephrine, cytokine production and activates functions of innate immune cells. NGF involves in multiple mechanisms regulating the immune response. Interestingly, studies on a small group of patients with cardiovascular disease or the metabolic syndrome (MetSyn) [17] have reported a systemic NGF deficit. NGF possibly links to the MetSyn and other inflammatory-related diseases [27]. The aim of the present study is to investigate whether the serum level of NGF is linked to cytokines in low-grade chronic inflammation in polycystic ovary syndrome.

\section{Materials \& Methods}

\subsection{Participants}

Totally 85 PCO patients (case group) and 86 non PCO infertile women in control group were selected randomly 
using random number table. All women were visited in a clinic affiliated to Tehran University of Medical Sciences for the first time between February-October 2013. The diagnosis of PCOS was made according to the joint criteria of the European Society of Human Reproduction and Embryology and the American Society of Reproductive Medicine (ESHRE/ASRM) [2]. The study objectives were explained to the patients before they entered the study, and an informed consent was obtained from all.

All women aged 20 - 40 years and had a BMI under 28. Demographic questionnaire was used in this study.

\subsection{Clinical and Laboratory Investigation}

Blood sample was obtained from all participants before $8 \mathrm{AM}$. Serum samples for all patients were obtained by centrifugation at $3000 \mathrm{rpm}$ for $10 \mathrm{~min}$, then liquated and stored at $-80^{\circ} \mathrm{C}$ until analysis. Concentration of NGF (ELISA kit, Cousabio from USA) and interleukins IL- $1 \alpha$, IL-1 $\beta$, IL-17 and tumor necrosis factor (TNF $\alpha$ ) (ELISA kit, Monobind from Austria) were measured in serum. This study was approved in ethical committee of Tehran University of Medical Sciences.

\subsection{Statistical Analysis}

The quantitative variables were presented with mean and standard deviation. Serum levels of NGF and interleukins IL- $1 \alpha$, IL-1 $\beta$, IL-17 and tumor necrosis factor (TNF $\alpha$ ) were compared between study groups with $\mathrm{t}$ test. The qualitative variables were presented with count and percentage and were compared between study groups with chi square test. According to departure from normal distribution, the mean, standard error of the mean and median were used for presenting concentrations of inflammatory cytokines, and for comparing of those variables between two study groups, Mann-Whitney nonparametric test was used. Spearman rank correlation coefficient was used for assessing inter-correlation between cytokines. Multinomial linear regression model was used to delete the effect of confounding factors. In this analysis age (year), BMI $\left(\mathrm{kg} / \mathrm{m}^{2}\right)$, occupation, menstrual status, frequency of dysmenorrhea, hirsutism and inflammatory cytokines were included in the model as confounders. Suffering from PCOS was the independent variable. Analysis was done in IBM SPSS 19 (SPSS Inc, Chicago Ill). $P$ value less than 0.05 was considered as significant level.

\section{Results}

Demographic characteristics of two groups are presented in Table 1. The symptoms of PCOS were significantly higher in PCOS patients (Table 2). The symptoms include irregular cycles (menstrual state) and hirsutism was significant between the two groups. Levels of circulating NGF in PCO patients and control subjects are displayed in Figure 1. Serum level of NGF $\alpha$ in PCOS patient was significantly lower than control group ( $p<$ 0.001). Concentration of IL17 in PCOS group was significantly lower than control group $(p<0.001)$. Median of IL-17 in PCOS group was $3.50(\mathrm{pg} / \mathrm{ml})$ and in control group was $16.30(\mathrm{pg} / \mathrm{ml})$. Both IL- $1 \alpha(p<0.001)$ and $\operatorname{IL1} \beta(p=0.017)$ serum levels were significantly higher in PCOS than control group (Figure 2). Serum concentration of TNF $\alpha$ had not difference between two groups $(p=0.119)$. Regression analysis showed that after adjusting for age, BMI, occupation status and PCOS symptoms inflammatory cytokines NGF $\alpha$ still were lower in PCOS patients in comparison to control group (Table 3). According to regression analysis IL1 $\beta$ had direct and $\mathrm{TNF} \alpha$ had indirect correlation with NGF $\alpha$.

Table 1. Comparison of quantitative factors between groups.

\begin{tabular}{|c|c|c|c|c|c|}
\hline \multirow{2}{*}{ Variables } & \multicolumn{2}{|c|}{ Control $(\mathrm{n}=86)$} & \multicolumn{2}{|c|}{$\operatorname{PCOS}(n=85)$} & \multirow{2}{*}{$\begin{array}{c}p \text {-value } \\
\text { t test }\end{array}$} \\
\hline & Mean & Standard deviation & Mean & Standard deviation & \\
\hline Age (year) & 29.5 & 5.1 & 27.1 & 4.4 & 0.001 \\
\hline Duration of marriage (year) & 6.88 & 4.01 & 6.52 & 3.42 & 0.537 \\
\hline Duration of infertility (year) & 4.33 & 3.96 & 4.84 & 3.22 & 0.365 \\
\hline Body mass index $\left(\mathrm{kg} / \mathrm{m}^{2}\right)$ & 25.41 & 3.76 & 27.39 & 3.94 & 0.001 \\
\hline Gravidity & 0.40 & 0.69 & 0.41 & 0.75 & 0.863 \\
\hline Parity & 0.19 & 0.42 & 0.23 & 0.45 & 0.499 \\
\hline
\end{tabular}




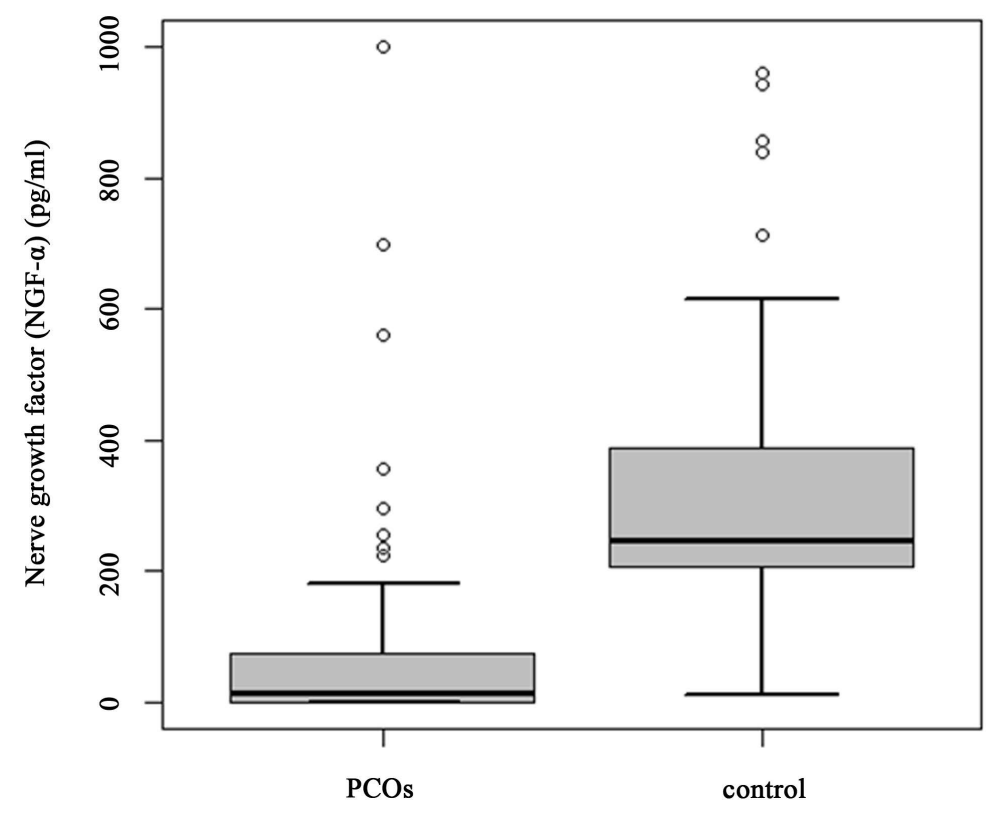

Figure 1. NGF $\alpha$ in PCOS and control group.
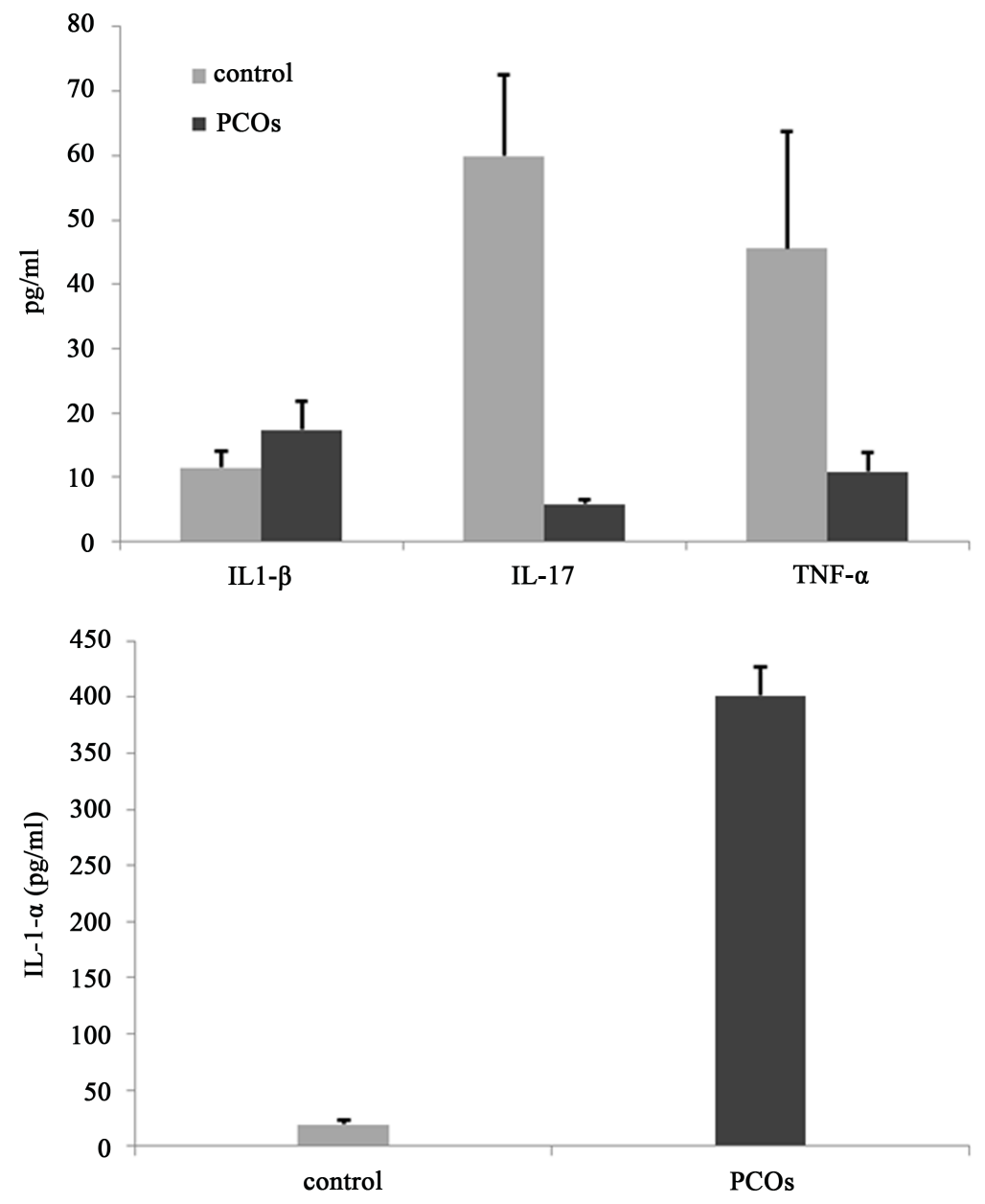

Figure 2. Inflammatory cytokines in PCOS patient and control group. 
Table 2. Comparison of qualitative factors between groups.

\begin{tabular}{|c|c|c|c|c|c|c|}
\hline \multirow{2}{*}{ Variables } & & \multicolumn{2}{|c|}{ Control } & \multicolumn{2}{|c|}{ PCOS } & \multirow{2}{*}{$p$-value } \\
\hline & & $\mathrm{n}$ & $\%$ & $\mathrm{n}$ & $\%$ & \\
\hline & Less than 12 & 27 & $31.40 \%$ & 30 & $35.29 \%$ & \\
\hline \multirow[t]{2}{*}{ Education (year) } & 12 (diploma) & 46 & $53.49 \%$ & 43 & $50.59 \%$ & 0.864 \\
\hline & More than 12 & 13 & $15.12 \%$ & 12 & $14.12 \%$ & \\
\hline \multirow[t]{2}{*}{ Occupation } & Housewife & 14 & $16.28 \%$ & 2 & $2.35 \%$ & 0.002 \\
\hline & Occupied & 72 & $83.72 \%$ & 83 & $97.65 \%$ & \\
\hline \multirow[t]{2}{*}{ Abortion } & No & 72 & $83.72 \%$ & 76 & $89.41 \%$ & 0.275 \\
\hline & Yes & 14 & $16.28 \%$ & 9 & $10.59 \%$ & \\
\hline \multirow[t]{2}{*}{ Infertility type } & Primary & 59 & $68.60 \%$ & 59 & $69.41 \%$ & 0.909 \\
\hline & Secondary & 27 & $31.40 \%$ & 26 & $30.59 \%$ & \\
\hline \multirow[t]{2}{*}{ Menstrual state } & Regular & 71 & $82.56 \%$ & 27 & $31.76 \%$ & $<0.001$ \\
\hline & Irregular & 15 & $17.44 \%$ & 58 & $68.24 \%$ & \\
\hline \multirow[t]{2}{*}{ Hirsutism } & No & 68 & $79.07 \%$ & 37 & $43.53 \%$ & $<0.001$ \\
\hline & Yes & 18 & $20.93 \%$ & 48 & $56.47 \%$ & \\
\hline \multirow[t]{2}{*}{ PAINFUL menstrual } & No & 23 & $26.74 \%$ & 11 & $12.94 \%$ & 0.024 \\
\hline & Yes & 63 & $73.26 \%$ & 74 & $87.06 \%$ & \\
\hline
\end{tabular}

Table 3. Regression model of NGF- $\alpha$ (Regression model $\left.\mathrm{R}^{2}=0.388\right)$.

\begin{tabular}{|c|c|c|c|c|c|}
\hline & \multicolumn{2}{|c|}{ Unstandardized coefficients } & \multirow{2}{*}{ Standardized coefficients } & \multirow{2}{*}{$\mathrm{t}$} & \multirow{2}{*}{$p$-value } \\
\hline & B & Std. error & & & \\
\hline Model constant & 527.81 & 288.13 & & 1.832 & 0.069 \\
\hline BMI & -8.65 & 6.59 & -0.095 & -1.312 & 0.192 \\
\hline Age & -5.01 & 5.43 & -0.069 & -0.923 & 0.358 \\
\hline Occupation & 71.02 & 87.14 & 0.057 & 0.815 & 0.416 \\
\hline Painful menstrual & 11.29 & 62.45 & 0.013 & 0.181 & 0.857 \\
\hline Irregular menstrual & 41.54 & 58.85 & 0.057 & 0.706 & 0.481 \\
\hline Hirsutism & 128.18 & 57.43 & 0.173 & 2.232 & 0.027 \\
\hline IL- $1 \alpha$ & -0.23 & 0.16 & -0.156 & -1.417 & 0.159 \\
\hline $\mathrm{IL}-1 \beta$ & 5.56 & 0.83 & 0.517 & 6.717 & $<0.001$ \\
\hline IL-17 & -0.39 & 0.31 & -0.094 & -1.288 & 0.200 \\
\hline TNF- $\alpha$ & -0.76 & 0.25 & -0.231 & -3.034 & 0.003 \\
\hline PCOS & -287.25 & 93.72 & -0.397 & -3.065 & 0.003 \\
\hline
\end{tabular}

\section{Discussion}

It is well known that one of the major neurotransmitters that control LH secretion is noradrenaline (NA). As women with PCOS have significantly higher sympathetic nerve activity than their matched controls, the in- 
creased sympathetic outflow may be related to hormonal and metabolic features that may be relevant to the pathophysiology of the syndrome [21]. Evidence from studies on women with PCO and on an experimental rat PCO model suggests that the sympathetic regulatory drive to the ovary may be unbalanced. Most reports support the theory that increased sympathetic activity contributes to the development and maintenance of PCOS. The results of our study in 2011 showed that antagonized the hyperactivity of the sympathetic nervous system results in the treatment of PCO modeling in rat [28]. Sympathetic hyperactivity is a hallmark of NGF over expression in peripheral tissues [29], including the ovary [7] [8]. Furthermore, sympathetic hyperactivity in PCOS has been suggested by indirect methods [30] and direct measurement of sympathetic nerve activity [31]. The development and function of ovarian sympathetic innervation depend on the ability of the ovaries to produce NGF [3]. Experimental study of Schmidt et al. in 2000 demonstrated that concentration of ovarian p75NTR mRNA and protein increase at both 30 and 60 days after EV injection. Elevated levels of NGF have been found to induce morphological and neurochemical alterations in sympathetic neurons, including axonal sprouting and increased levels of p75NTR mRNA [32]. Injection of EV resulted in higher intra-ovarian synthesis of NGF and p75NTR after 30 days, an effect that was still measurable after 60 days, the last time-point checked. This time period coincided with the time necessary for the sympathetic tone in the ovary to increase, which precedes the appearance of follicular cysts [9]. It is known that p75NTR aids the development of specific populations of sympathetic neurons [33] and that this receptor is responsible for the responsiveness of adult sympathetic neurons to target-derived NGF [34]. It is therefore possible that the activation of p75NTR by NGF is part of an important mechanism in the pathogenesis of PCO. Dissen et al. in 2009 collected granulosa cells and follicular fluid from follicular aspirates of women with and without PCOS undergoing routine in vitro fertilization [7]. NGF levels were increased in follicular fluid (twofold) and granulosa cell conditioned medium (sixfold), in PCOS women compared with controls. The authors went on to selectively over express NGF in ovarian thecal/interstitial cells by generating transgenic mice carrying the NGF gene under the control of the 17- $\alpha$ hydroxylase/C17-20 lyase promoter. Transgenic mice had a greater density of tyrosine hydroxylase-positive nerve fibers in the ovary, reflecting sympathetic innervation, increased androgen production in response to FSH-like activity and a higher prevalence of follicular cysts following sustained increases in LH [35]. The higher sympathetic neural density supports the findings of Heider et al., who found a higher density of catecholaminergic fibers in human polycystic ovaries compared with controls. These studies suggest that sympathetic overactivity and ovarian NGF excess play an important role in PCO morphology [5] [36]. In 2000 Stener-Victorin et al., found that repeated EA treatments in the steroid-induced rat PCO model used in this study significantly reduced increased concentrations of ovarian NGF and of median eminence (ME) corticotropin-releasing factor (CRF) [37], which indicates a functional interaction between activity in the nervous and endocrine systems. These findings show that repeated EA treatments in the steroid-induced rat PCO model can be firstly resulted down-regulation of NGF receptors (increased concentrations of ovarian NGF) and then reduced NGF [38]. The present study showed the significant reduction of NGF in serum of patients with PCO. Reduced plasma levels of NGF and BDNF have been associated with acute coronary syndromes and metabolic syndromes [36]. Peripheral cardiovascular risk factors such as abdominal obesity [39], dyslipidemia [40], glucose intolerance [41], and insulin resistance [42], known to be associated with PCOS, may per se provoke changes in sympathetic nerve activity. Now the question is whether decreased serum NGF can be considered characteristic of PCOS? NGF is a signaling and critical molecule for the survival and maintenance of sympathetic nervous system. On the other hand, inflammation is now considered to be an important feature of obesity, cardiovascular disease and metabolic syndrome (MetSyn). Chaldakov and coworkers in 2004 have hypothesized that a reduction in NT production could be implicated in the pathogenesis of obesity and related comorbidities, and reported that hyponeurotrophinemia was present in a group of patients with the MetSyn or cardiovascular disease and not in healthy subjects [17] [43] [44]. However, serum hyponeurotrophinemia in PCO patients can be following reasons: 1) PCOS like, MetSyn or cardiovascular disease occur by activation of hypothalamo-pituitary-adrenal (HPA) axis and sympathetic nervous system. 2) IL-1 can also modify noradrenaline (NA) turnover. Peripheral administration of IL-1 is known to activate the HPA axis and brain noradrenergic systems [14]. The effects of IL-1 $\beta$, an endogenous pyrogen, were investigated on both the central and peripheral endocrine, sympathetic, and cardiovascular systems. Administration of IL- $1 \beta$ to humans initiates a cascade of metabolic, hematologic, and cardiovascular events. Cardiovascular responses that occur early after IL- $1 \beta$ administration in humans are most likely the result of adrenergic stimulation possibly through its effect on the central nervous system [45]. 3) Cardiometabolic diseases (atherosclerosis, obesity, type 2 diabetes, metabolic syndrome, and type3 diabetes) [46] are all risk factors in PCOS. 4) Neurotrophin re- 
lease and thus receptor activation, varies among somatic tissues and physiological state. Thus characteristic electrical properties of sympathetic neurons can regulate the functional output of the sympathetic nervous system [47]. Therefore the neurotrophic factors are involved in the pathogenesis of diabetic polyneuropathy [48]. 5) MetSyn and obesity are associated with the chronic low-grade inflammation [49]; serum NT levels (neurotrophinemia) could play an important role in the ethiopathogenic mechanisms in PCOS. 6) The higher sympathetic tone is confirmed within PCOS, Chronic inflammatory and/or psychoemotional distress provoke a series of neuroimmunoendocrine interactions such as increased tissue and plasma levels of proinflammatory cytokines and neurotrophins, vegetodystonia, disbalance of neurotransmitters, hormones and immunity markers, activation of the HPA axis, insulin resistance, and atherosclerosis. Our works in 2011 confirmed overactivity in sympathetic nervous system in rat modeling of PCOS [28] [50] and in women with PCO [51]. In the present study serum IL $1 \alpha$ and $\beta$ increased which confirms other researches. The reduction of IL17 $\alpha$ can be reason of NA reaction in PCO women. The regression analysis IL-1 $\beta$ had direct correlation with NGF $\alpha$ in PCO women. The reduction of NGF $\alpha$ in serum of these patients can be reason of psychoemotional distress in PCO women. Acute stress results in an increase in NGF serum levels, while repeated stress paradigm might result in a long term down-regulation of NGF levels [52]. Chronic stress, chronic HPA axis hyperactivity in pathological conditions which might result in a long term down regulation in NGF synthesis [53]. Furthermore, it is not clear whether changes in serum neurotrophins levels result from decreased/increased levels of neurotrophins in the brain, peripheral tissues, or both; however, a tendency toward a correlation between serum and CSF levels suggests that the two compartments might communicate [54]. Furthermore, low NGF serum levels might be due to a reduced synthesis and/or release of NGF or to an enhanced uptake in the NGF-responsive cells [55]. NGF and NA in the ovaries of women with PCOS are high. On the other hand women with PCOS exhibit significantly more emotional distress compared with women without PCOS [56]. However, distress scores mostly remain within the normal range. The cause of emotional distress could only partly be explained by methodological or clinical features [57].

\section{Conclusion}

Hyponeurotrophinemia set point in women with PCOS could reflect two aspects: 1) deficit of neuronal stress-adaptation in PCO patients and 2) high uptake of NGF by the ovaries of PCO women which can be caused by an overactive sympathetic nervous system in ovary. These considerations could hypothetically account for lower baseline NGF levels in serum of these patients compared to healthy controls.

\section{Acknowledgements}

This work was supported by the Research Council of Tehran University of Medical Sciences, Tehran, Iran (publication No. 39-19492, revised 2012).

\section{Conflict of Interests}

There is no conflict of interest among the authors.

\section{References}

[1] Moran, L.J., Hutchison, S.K., Norman, R.J. and Teede, H.J. (2011) Lifestyle Changes in Women with Polycystic Ovary Syndrome. The Cochrane Database of Systematic Reviews, 162, CD007506.

[2] Rotterdam ESHRE/ASRM-Sponsored PCOS Consensus Workshop Group (2004) Revised 2003 Consensus on Diagnostic Criteria and Long-Term Health Risks Related to Polycystic Ovary Syndrome. Fertility and Sterility, 81, 19-25.

[3] Lara, H.E., Ferruz, J.L., Luza, S., Bustamante, D.A., Borges, Y. and Ojeda, S.R. (1993) Activation of Ovarian Sympathetic Nerves in Polycistic Ovary Syndrome. Endocrinology, 133, 2690-2695.

[4] Semenova, I. (1969) Adrenergic Innervation of the Ovaries in Stein-Leventhal Syndrome. Vestn Akad Med Nauk SSSR, 24, 58-62.

[5] Heide, U., Pedal, I. and Spanel-Borowski, K. (2001) Increase in Nerve Fibers and Loss of Mast Cells in Polycystic and Postmenopausal Ovaries. Fertility and Sterility, 75, 1141-1147.

[6] Lobo, R.A., Granger, L.R., Paul, W.L., Goebelsmann, U. and Mishell Jr., D.R. (1983) Psychological Stress and Increases in Urinary Norepinephrine Metabolites, Platelet Serotonin, and Adrenal Androgens in Women with Polycystic 
Ovary Syndrome. American Journal of Obstetrics \& Gynecology, 145, 496-503.

[7] Dissen, G.A., Garcia-Ruda, C. and Paredes, A. (2009) Excessive Ovarian Production of Nerve Growth Factor Facilitates Development of Cystic Ovarian Morphology in Mice and Is a Feature of Polycystic Ovarian Syndrome in Humans. Endocrinology, 150, 2906-2914.

[8] Lara, H.E., Dissen, G.A., Leylon, V., Paredes, A., Fuenzalida, H., Fedler, J.L. and Ojeda, S.R. (2000) An Increased Intraovarian Synthesis of Nerve Growth Factor and Its Low Affinity Receptor Is a Principal Component of Steroid-Induced Polycystic Ovary in the Rat. Endocrinology, 141, 1059-1072.

[9] Repaci, A., Gambineri, A. and Pasquali, R. (2011) The Role of Low-Grade Inflammation in the Polycystic Ovary Syndrome. Molecular and Cellular Endocrinology, 335, 30-41.

[10] Fernandez-Real, J.M. and Ricart, W. (2003) Insulin Resistance and Chronic Cardiovascular Inflammatory Syndrome. Endocrine Reviews, 24, 278-301.

[11] Escobar-Morreale, H.F., Luque-Ramirez, M. and San Millan, J.L. (2005) The Molecular-Genetic Basis of Functional Hyperandrogenism and the Polycystic Ovary Syndrome. Endocrine Reviews, 26, 251-282. http://dx.doi.org/10.1210/er.2004-0004

[12] Reis, F.M., Cobellis, L., Luisi, S., Driul, L., Florio, P., Faletti, A. and Petraglia, F. (2000) Paracrine/Autocrine Control of Female Reproduction. Gynecological Endocrinology, 14, 464-475. http://dx.doi.org/10.3109/09513590009167720

[13] Dinarello, C.A. (1998) Interleukin-1, Interleukin-1 Receptors and Interleukin-1 Receptor Antagonist. International Reviews of Immunology, 16, 457-499. http://dx.doi.org/10.3109/08830189809043005

[14] Smagin, G.N., Swiergiel, A.H. and Dunn, A.J. (1996) Peripheral Administration of Interleukin-1 Increases Extracellular Concentrations of Norepinephrine in Rat Hypothalamus: Comparison with Plasma Corticosterone. Psychoneuroendocrinology, 21, 83-93. http://dx.doi.org/10.1016/0306-4530(95)00019-4

[15] Chuluyan, H., Saphier, D., Rohn, W. and Dunn, A.J. (1992) Noradrenergic Innervation of the Hypothalamus Participates in the Adrenocortical Responses to Interleukin-1. Neuroendocrinology, 56, 106-111. http://dx.doi.org/10.1159/000126215

[16] Kolbus, A., Walch, K., Nagele, F., Wenzl, R., Unfried, G. and Huber, C.J. (2007) Interleukin-1 Alpha but Not Interleukin-1 Beta Gene Polymorphism Is Associated with Polycystic Ovary Syndrome. Journal of Reproductive Immunology, 73, 188-193. http://dx.doi.org/10.1016/j.jri.2006.08.002

[17] Chaldakov, G.N., Fiore, M., Stankulov, I.S., Manni, L., Hristova, M.G., Antonelli, A., Ghenev, P.I. and Aloe, L. (2004) Neurotrophin Presence in Human Coronary Atherosclerosis and Metabolic Syndrome: A Role for NGF and BDNF in Cardiovascular Disease? Progress in Brain Research, 146, 279-289.

[18] Atsumi, T., Singh, R., Sabharwal, L., Bando, H., Meng, J., Arima, Y., Yamada, M., Harada, M., Jiang, J.J., Kamimura, D., Ogura, H., Hirano, T. and Murakami, M. (2014) Inflammation Amplifier, a New Paradigm in Cancer Biology. Cancer Research, 74, 8-14. http://dx.doi.org/10.1158/0008-5472.CAN-13-2322

[19] Chaves, R.N., Alves, A.M., Lima, L.F., Matos, H.M., Rodrigues, A.P. and Figueiredo, J.R. (2013) Role of Nerve Growth Factor (NGF) and Its Receptors in Folliculogenesis. Zygote, 21, 187-197. http://dx.doi.org/10.1017/S0967199412000111

[20] Dissen, G.A., Paredes, A., Romero, C., Dees, W.L. and Ojeda, S.R. (2004) Neural and Neurotrophic Control of Ovarian Development. In: Leung, P. and Adashi, E., Eds., the Ovary, 2nd Edition, Academic Press, San Diego, 3-23.

[21] Dissen, G.A., Hill, D.F., Costa, M.E., Les Dees, C.W., Lara, H.E. and Ojeda, S.R. (1996) A Role for Trka Nerve Growth Factor Receptors in Mammalian Ovulation. Endocrinology, 137, 198-209.

[22] Dissen, G.A., Parrott, J.A., Skinner, M.K., Hill, D.F., Costa, M.E. and Ojeda, S.R. (2000) Direct Effects of Nerve Growth Factor on Thecal Cells from Antral Ovarian Follicles. Endocrinology, 141, 4736-4750.

[23] Dissen, G.A., Lara, H.E., Leyton, V., Paredes, A., Hill, D.F., Costa, M.E., Martinez-Serrano, A. and Ojeda, S.R. (2000) Intraovarian Excess of Nerve Growth Factor Increases Androgen Secretion and Disrupts Estrous Cyclicity in the Rat. Endocrinology, 141, 1073-1082.

[24] Garcia-Rudaz, C., Mayerhofer, A., Ojeda, S.R. and Dissen, G.A. (2008) An Excessive Ovarian Production of Nerve Growth Factor (NGF) Facilitates the Development of Polycystic Ovarian Morphology in Mice and Is a Discernible Feature of Polycystic Ovarian Syndrome (PCOS) in Humans. Program of the 90th Annual Meeting of the Endocrine Society, San Francisco. (Abstract P483).

[25] Gore-Langton, R.E. and Armstrong, D.T. (1994) Follicular Steroidogenesis and Its Control. In: Knobil, E. and Neill, J.D., Eds., the Physiology of Reproduction, 2nd Edition, Raven Press, Ltd., New York, 571-627.

[26] Carr, M.J. and Undem, B.J. (2001) Inflammation-Induced Plasticity of the Afferent Innervation of the Airways. Environmental Health Perspectives, 109, 567-571. http://dx.doi.org/10.1289/ehp.01109s4567 
[27] Bulló, M., Peeraully, M.R., Trayhurn, P., Folch, J. and Salas-Salvadó, J. (2007) Circulating Nerve Growth Factor Levels in Relation to Obesity and the Metabolic Syndrome in Women. European Journal of Endocrinology, 157, 303-310. http://dx.doi.org/10.1530/EJE-06-0716

[28] Zangeneh, F.Z., Mohammadi, A., Ejtemaeimehr, S.H., Naghizadeh, M.M. and Fatemeh, A. (2011) The Role of Opioid System and Its Interaction with Sympathetic Nervous System in the Processing of Polycystic Ovary Syndrome Modeling in Rat. Archives of Gynecology and Obstetrics, 283, 885-892. http://dx.doi.org/10.1007/s00404-010-1776-7

[29] Dissen, G.A. and Ojeda, S.R. (2004) Transgenic Expression of Nerve Growth Factor (NGF) Targeted to Ovarian Androgen-Producing Cells Delays Pubertal Development and Compromises Fertility. Program of the 86th Annual Meeting of the Endocrine Society, New Orleans, 212. (Abstract P242)

[30] Stener-Victorin, E., Lundeberg, T., Waldenström, U., Manni, L., Aloe, L., Gunnarsson, S. and Janson, P.O. (2000) Effects of Electro-Acupuncture on Nerve Growth Factor in Rats with Experimentally Induced Polycystic Ovaries. Biology of Reproduction, 63, 1507-1513.

[31] Edwards, R.H., Rutter, W.J. and Hanahan, D. (1989) Directed Expression of NGF to Pancreatic $\beta$ Cells in Transgenic Mice Leads to Selective Hyperinnervation of the Islets. Cell, 58, 161-170. http://dx.doi.org/10.1016/0092-8674(89)90412-1

[32] Schmidt, R.E., Dorsey, D.A., Roth, K.A., Parvin, C.A., Hounsom, L. and Tomlinson, D.R. (1994) Effect of Streptozotocin-Induced Diabetes on NGF, p75(NTR) and TrkA Content of Prevertebral and Paravertebral Rat Sympathetic Ganglia. Brain Research, 867, 149-156. http://dx.doi.org/10.1016/S0006-8993(00)02281-2

[33] Lee, K.F., Bachman, K., Landis, S. and Jaenisch, R. (1994) Dependence on p75 for Innervation of Some Sympathetic Targets. Science, 263, 1447-1449. http://dx.doi.org/10.1126/science.8128229

[34] Cowen, T. and Gavazzi, I. (2005) Plasticity in Adult and Ageing Sympathetic Neurons. Progress in Neurobiology, 54, 249-288. http://dx.doi.org/10.1016/S0301-0082(97)00071-3

[35] Lansdown, A.L. and Rees, D.A. (2012) The Sympathetic Nervous System in Polycystic Ovary Syndrome: A Novel Therapeutic Target? Clinical endocrinology (Oxford), 77, 791-801. http://dx.doi.org/10.1111/cen.12003

[36] Manni, L., Nikolova, V., Vyagova, D., Chaldakov, G.N. and Aloe, L. (2004) Reduced Plasma Levels of NGF and BDNF in Patients with Acute Coronary Syndromes. International Journal of Cardiology, 102, 169-171. http://dx.doi.org/10.1016/j.ijcard.2004.10.041

[37] Stener-Victorin, E., Lundeberg, T., Cajander, S., Aloe, L., Manni, L., Waldenström, U. and Janson, P.O. (2003) Steroid-Induced Polycystic Ovaries in Rats: Effect of Electro-Acupuncture on Concentrations of Endothelin-1 and Nerve Growth Factor (NGF), and Expression of NGF mRNA in the Ovaries, the Adrenal Glands, and the Central Nervous System. Reproductive Biology and Endocrinology, 1, 33-40. http://dx.doi.org/10.1186/1477-7827-1-33

[38] Manni, L., Holmäng, A., Lundeberg, T., Aloe, L., Stener-Victorin, E. (2005) Ovarian Expression of Alpha (1)- and Beta (2)-Adrenoceptors and p75 Neurotrophin Receptors in Rats with Steroid-Induced Polycystic Ovaries. Autonomic Neuroscience, 118, 79-87. http://dx.doi.org/10.1016/j.autneu.2005.01.004

[39] Jones, P.P., Davy, K.P., Alexander, S. and Seals, D.R. (1997) Age-Related Increase in Muscle Sympathetic Nerve Activity Is Associated with Abdominal Adiposity. American Journal of Physiology, Endocrinology and Metabolism, 272, E976-E980.

[40] Kim, J.J. and Choi, Y.M. (2013) Dyslipidemia in Women with Polycystic Ovary Syndrome. Obstetrics \& Gynecology Science, 56, 137-142. http://dx.doi.org/10.5468/ogs.2013.56.3.137

[41] Celik, C., Tasdemir, N., Abali, R., Bastu, E. and Yilmaz, M. (2014) Progression to Impaired Glucose Tolerance or Type 2 Diabetes Mellitus in Polycystic Ovary Syndrome: A Controlled Follow-Up Study. Fertility and Sterility, 101, 1123-1128.

[42] Kaaja, R.J. and Poyhonen-Alho, M.K. (2006) Insulin Resistance and Sympathetic Overactivity in Women. Journal of Hypertension, 24, 131-141. http://dx.doi.org/10.1097/01.hjh.0000194121.19851.e5

[43] Chaldakov, G.N., Fiore, M., Hristova, M.G. and Aloe. L, (2003) Metabotrophic Potential of Neurotrophins: Implication in Obesity and Related Diseases? Medical Science Monitor, 9, HY19-HY21.

[44] Chaldakov, G.N., Stankulov, I.S., Fiore, M., Ghenev, P.I. and Aloe, L. (2001) Nerve Growth Factor Levels and Mast Cells Distribution in Human Coronary Atherosclerosis. Atherosclerosis, 159, 57-66. http://dx.doi.org/10.1016/S0021-9150(01)00488-9

[45] Haefeli, W.E., Bargetzi, M.J., Starnes, H.F., Blaschke, T.F. and Hoffman, B.B. (1993) Evidence for Activation of the Sympathetic Nervous System by Recombinant Human Interleukin-1 Beta in Humans. Journal of Immunotherapy with Emphasis on Tumor Immunology, 13, 136-140. http://dx.doi.org/10.1097/00002371-199302000-00009

[46] Luther, J.A. and Birren, S.J. (2009) p75 and TrkA Signaling Regulates Sympathetic Neuronal Firing Patterns via Differential Modulation of Voltage-Gated Currents. The Journal of Neuroscience, 29, 5411-5424. http://dx.doi.org/10.1523/JNEUROSCI.3503-08.2009 
[47] Apfel, S. (1999) Neurotrophic Factors and Diabetic Peripheral Neuropathy. European Neurology, 41, 27-34. http://dx.doi.org/10.1159/000052077

[48] Chaldakov, G.N., Tonchev, A.B. and Manni, L. (2007) Brain-Derived Neurotrophic Factor (BDNF) and Type 2 Diabetes. Diabetologia, 50, 431-438.

[49] Hristova, M.G. (2013) Metabolic Syndrome-from the Neurotrophic Hypothesis to A Theory. Medical Hypotheses, 81, 627-634. http://dx.doi.org/10.1016/j.mehy.2013.07.018

[50] Zangeneh, F.Z., Abdollahi, A., Tavassoli, P. and Naghizadeh, M.M. (2011) The Effect of Cold Stress on Polycystic Ovary Syndrome in Rat: Before and during Modeling. Archives of Gynecology, 284, 651-657. http://dx.doi.org/10.1007/s00404-010-1711-y

[51] Zangeneh, F.Z., Naghizadeh, M.M., Abdollahi, A. and Abedinia, N. (2015) Opioid System ( $\beta$-Endorphin) and Stress Hormones Profiling in Women with Polycystic Ovary Syndrome. Annual Research \& Review in Biology, 5, 409-418. http://dx.doi.org/10.9734/ARRB/2015/12932

[52] Alleva, E., Petruzzi, S., Cirulli, F. and Aloe, L. (1996) NGF Regulatory Role in Stress and Coping of Rodents and Humans. Pharmacology Biochemistry and Behavior, 54, 65-72. http://dx.doi.org/10.1016/0091-3057(95)02111-6

[53] Aisa, B., Gil-Bea, F.J., Marcos, B., Tordera, R., Lasheras, B., Del Rio, J. and Ramirez, M.J. (2009) Neonatal Stress Affects Vulnerability of Cholinergic Neurons and Cognition in the Rat: Involvement of the HPA Axis. Psychoneuroendocrinology, 34, 1495-1505. http://dx.doi.org/10.1016/j.psyneuen.2009.05.003

[54] Cirulli, F. and Alleva, E. (2009) The NGF Saga from Animal Models of Psychosocial Stress to Stress-Related psychopathology. Frontiers in Neuroendocrinology, 30, 379-395. http://dx.doi.org/10.1016/j.yfrne.2009.05.002

[55] Aloe, L., Alleva, E. and Fiore, M. (2002) Stress and Nerve Growth Factor: Findings in Animal Models and Humans. Pharmacology Biochemistry and Behavior, 73, 159-166. http://dx.doi.org/10.1016/S0091-3057(02)00757-8

[56] Zangeneh, F.Z., Jafarabadi, M., Naghizadeh, M.M., Abedinia, N. and Haghollahi, F. (2012) Psychological Distress in Women with Polycystic Ovary Syndrome from Imam Khomeini Hospital, Tehran. Journal of Reproduction \& Infertility, 13, 111-115.

[57] Veltman-Verhulst, S.M., Boivin, J., Eijkemans, M.J. and Fauser, B.J. (2012) Emotional Distress Is a Common Risk in Women with Polycystic Ovary Syndrome: A Systematic Review and Meta-Analysis of 28 Studies. Human Reproduction Update, 18, 638-651. http://dx.doi.org/10.1093/humupd/dms029 